\title{
INFLUENCE OF LEADING EDGE BLUNTNESS ON HYPERSONIC FLOW IN A GENERIC INTERNAL-COMPRESSION INLET
}

\section{Borovoy, I. Egorov, V. Mosharov, V. Radchenko, A. Skuratov, and I. Struminskaya}

Central Aerohydrodynamic Institute (TsAGI) 1 Zhukovsky Str., Zhukovsky, Moscow Region 140180, Russia

\begin{abstract}
Flow and heat transfer inside a generic inlet are investigated experimentally. The cross section of the inlet is rectangular. The inlet is installed on a flat plat at a significant distance from the leading edge. The experiments are performed in TsAGI wind tunnel UT-1M working in the Ludwieg tube mode at Mach number $\mathrm{M}_{\infty}=5$ and Reynolds numbers (based on the plate length $L=320 \mathrm{~mm}$ ) $\operatorname{Re}_{\infty L}=23 \cdot 10^{6}$ and $13 \cdot 10^{6}$. Steady flow duration is $40 \mathrm{~ms}$. Optical panoramic methods are used for investigation of flow outside and inside the inlet as well. For this purpose, the cowl and one of two compressing wedges are made of a transparent material. Heat flux distribution is measured by thin luminescent Temperature Sensitive Paint (TSP). Surface flow and shear stress visualization is performed by viscous oil containing luminophor particles. The investigation shows that at high contraction ratio of the inlet, an increase of plate or cowl bluntness to some critical value leads to sudden change of the flow structure.
\end{abstract}

\section{INTRODUCTION}

Structure of the flow in the inlet has a big impact on the characteristics of the hypersonic vehicle. Many works are dedicated to investigation of inlets [124]. Various aerodynamic schemes were considered: with external, internal, and combined gas compression. Integral inlet characteristics were studied: mass flow rate, pressure recovery, and external drag.

It is evident that at high flight velocities, the leading edges of the inlet should be blunted to decrease the surface temperature. However, just few studies examine the effect of leading edges bluntness on the inlet characteristics. According to [5], the leading edge bluntness can result in significant decrease of pressure 
recovery and mass flow rate. An influence of small bluntness on the flow over the external part of the inlet is studied in [13]. The present work is focused on the bluntness influence on the flow inside the inlet.

One more challenge is a starting of hypersonic inlet. Many papers are devoted to this problem $[1,9,10,12,17,19,20,22,23]$. Two distinct flow configurations can be formed in a hypersonic inlet with big area reduction. The first type is termed 'started' or 'regular' and is characterized by supersonic flow throughout the internal area. The second type is termed 'unstarted' and is characterized by bow wave, overboard spillage in front of the inlet, and subsonic flow inside it. An influence of leading edges bluntness on the inlet starting is studied in this work.

Most studies are dedicated to the integral inlet characteristics. Only few works are focused on the pressure and heat transfer distributions inside the inlet $[6,8,14,21]$. In this paper, the heat transfer and flow structure inside the inlet are investigated. This is possible through the use of optical panoramic methods based on the luminescent TSP coating and transparent walls of the inlet.

The present work is a continuation of [25-33]. In [25-27, 29,30,32], an influence of plate bluntness on the flow at oblique shock impingement is studied. Papers $[28,31]$ investigate influence of plate bluntness on the flow near a wedge and work [33] considers the flow near the intersecting shocks generated by double wedges. All the investigations show that the plate bluntness weakens heat transfer in the area where the shocks interact with the boundary layer. This is due to the reduction of gas density in the high entropy layer and the involvement of some part of the high entropy layer in the recirculation flow. In the case of double wedges, the plate blunting can lead to the channel blockage near the plate surface. In this case, two local separation zones generated near each wedge merge into a global separation zone. It starts ahead the wedges and finishes near the throat of the channel formed between the wedges.

\section{EXPERIMENTAL MODEL. FLOW CHARACTERISTICS}

Figure 1 presents the experimental model. The coordinate plane $X Z$ is located on the bottom plate with origin at its leading edge. The bottom plate 1 and the top plate 3 (cowl) are flat. Their bluntness can be varied in the range $0-4 \mathrm{~mm}$ using the changeable leading edges. The cowl is transparent behind the leading edge to provide the visibility of the flow inside the inlet. The shape of the model studied can be characterized by the following nondimensional values affecting the flow in the inlet: area reduction $\eta=W_{0} / W_{t}=4$, the relative distance of the inlet from the plate leading edge $X_{0} / W_{0}=1.29$, and the relative inlet height $H / W_{0}=0.8$. 


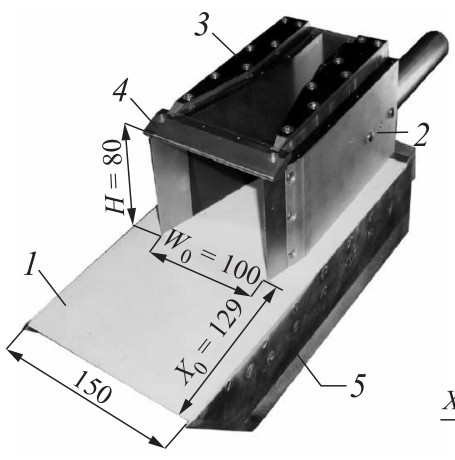

(a)

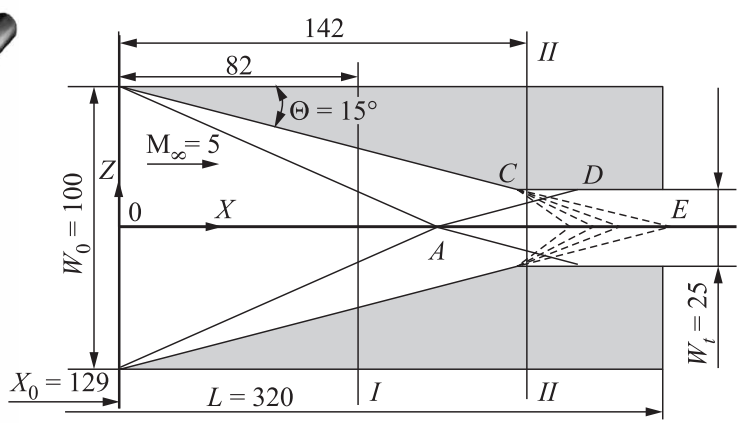

(b)

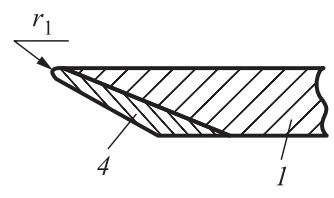

(c)

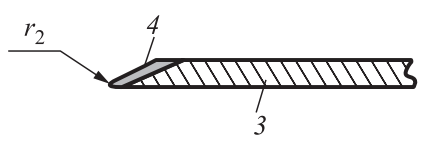

(d)

Figure 1 Model of inlet: $(a)$ photo; $(b)$ cross section of the wedges; $(c)$ cross section of the plate leading edge; and $(d)$ cross section of the cowl leading edge: 1 - bottom plate; 2 - wedges; 3 - cowl; 4 - changeable leading edges of the plate and the cowl; and 5 - side fences. Dimensions are in millimeters

Figure $1 b$ illustrates the shock waves and rarefaction waves in the twodimensional (2D) flow of nonviscous gas at $\mathrm{M}=5$. Behind the wedge shocks, the pressure is 4.8 times higher in respect with the undisturbed flow. The shock reflected from the symmetry line increases the pressure 3.4 times additionally. Thus, the pressure behind the point $A$ is 16.4 times higher than that in the undisturbed flow. Between the points $C$ and $D$, the pressure falls almost to the undisturbed level.

The tests are carried out in the TsAGI wind tunnel UT-1M. It worked in the Ludwieg-type mode. The duration of steady flow is $40 \mu \mathrm{s}$. The averaged characteristics of undisturbed flow are presented in Table 1.

Table 1 Flow characteristics at $\mathrm{M}=5$

\begin{tabular}{ccc}
\hline Reynolds number $\operatorname{Re}_{\infty L}$ & Total pressure $P_{t}$, bar & Total temperature $T_{t}, \mathrm{~K}$ \\
\hline $23 \cdot 10^{6}$ & 62.9 & 527 \\
$13 \cdot 10^{6}$ & 33.6 & 518 \\
\hline
\end{tabular}


Scatter of total pressure values in different runs is $\pm 6 \%$ of the mean pressure at $P_{t}=62.9$ bar and $\pm 10 \%$ at $P_{t}=33.6$ bar. The total temperature scatter is $\pm 2 \%$. The surface temperature was approximately $293 \mathrm{~K}$; so, at $\mathrm{M}_{\infty}=5$, the temperature factor $T_{w} / T_{0}=0.56$.

Some tests are performed at Mach number $\mathrm{M}_{\infty}=8$ and Reynolds numbers $\operatorname{Re}_{\infty L}=11 \cdot 10^{6}$ and $3.5 \cdot 10^{6}$.

\section{EXPERIMENTAL METHODS}

Thin luminescent temperature sensitive paint is used for investigation of heat exchange [28]. The method is based on the temperature quenching of luminescence of organic dye. The measured increase of temperature during the determined time interval is used to calculate the heat flux from gas to the surface in each point. To determine the temperature increase, two images of luminescence intensity distribution on the model surface are acquired during the test: the first one - before the test at the known temperature value of the model surface (wind-off image) and the second one - at the known time interval after flow start (wind-on image). The ratio of wind-off luminescence intensity to the windon one is determined by TSP temperature and is independent on TSP thickness and on the distribution of excitation light intensity. Unfortunately, excitation light intensity value is changed during acquisition of wind-off and wind-on images because of exciting-light source instability and of model displacement under an action of aerodynamic load. To exclude the effect of exciting-light variation, the binary (two-color) TSP containing two luminophores (active and reference) is used. Active luminophore is sensitive to the temperature, while reference luminophore is temperature insensitive and is used to determine the exciting-light intensity variation in each point of the model surface. Both luminophores are excited simultaneously by the same exciting light, but emit light of different spectral ranges that allows to acquire their images separately. Model surface temperature is calculated in each point of the visible surface using TSP calibration characteristic. This characteristic is determined by laboratory calibration of TSP sample prepared simultaneously with model preparation. Random error of temperature measurement is about $1 \mathrm{~K}$. Heat flux error is about $10 \%-15 \%$. The measurement results are presented as Stanton number distributions:

$$
\mathrm{St}=\frac{q}{\rho_{\infty} U_{\infty} c_{p}\left(T_{t}-T_{w}\right)}
$$

where $q$ is the measured heat flux; $\rho_{\infty}$ and $U_{\infty}$ are the density and velocity in the undisturbed flow; $T_{t}$ is the total temperature; $T_{w}$ is the model surface temperature (it changes insignificantly during experiment because of very short flow duration); and $c_{p}$ is the specific heat at constant pressure. 
The surface flow is visualized by the method recently developed at TsAGI [34]. It is based on measurements of small movements of oil marked by contrast fluorescent particles.

In this work, the described methods are used for investigation of external and internal flow as well. To do that, some parts of the cowl and one wedge are made of a material transparent to the exciting ultraviolet (UV) light and to the luminescent visible light. The transparent parts are used in two ways: $(i)$ to measure the heat flux to the transparent part; and (ii) to measure the heat flux to the opposite nontransparent surface. Thermal characteristics of appropriate material are used at solving the equation of heat transfer. The data presented below demonstrate a satisfactory agreement between the experimental results and calculated heat flux values on the cowl and on the plate under the cowl.

\section{FLOW SCHEMES}

Flow around the inlet installed on the plate at significant distance from its leading edge will be discussed. The flow schemes are based on the experimental data presented below and on the results of [33]. At high area reduction of the inlet (for example, at $\eta=W_{0} / W_{t}=4$ ), two flow schemes are possible (Fig. 2).

First, influence of plate bluntness on flow will be considered. When the plate leading edge is sharp or slightly blunted, the regular supersonic flow throughout the inlet takes place (Fig. $2 a$ ). In this case, the captured flow area is approximately equal to the inlet area. Inside the inlet, narrow separation zones are formed near the wedges on the plate and cowl surfaces. In these zones, the boundary layer and the high-entropy layer generated by the leading edge are

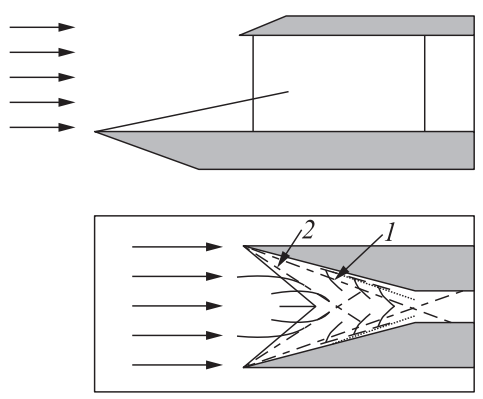

(a)
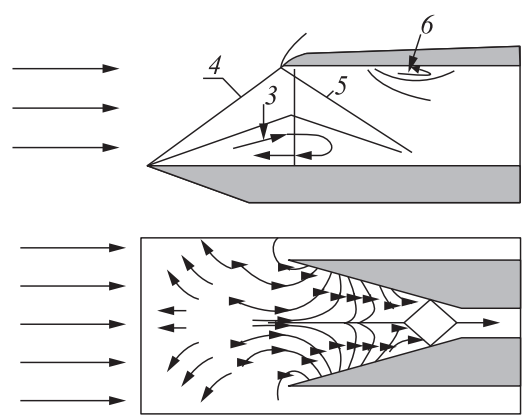

(b)

Figure 2 Flow schemes: (a) regular flow; and (b) blocking of the inlet: 1 - wedge shock; 2 - separation shock (separation line); 3 - global separation zone; 4 - shock of global separation; 5 - bow wave of the cowl; and 6 - separation zone on the cowl 
involved in the longitudinal motion. It means that the velocity vector forms an acute angle with the direction of undisturbed flow. When the high-entropy and boundary layers become thicker, the separation zones become wider, the separation lines are deflected upstream, the separation shocks become stronger, and the losses of total pressure are increased.

At the critical bluntness radius of the plate leading edge $\left(r_{1}^{*}\right)$, the pressure losses result in blocking of the channel section located near the plate: gas flowing near the plate cannot penetrate through the channel throat. As a result, two individual separation zones merge into a global separation zone (Fig. 2b). The separation line of the new separation zone jumps forward ahead the inlet. It is perpendicular to external flow direction. The separation shock 4 declines the flow from the plate toward the cowl. The cowl prevents gas outflow from the inlet. Therefore, at the cowl presence, the dimensions of the separation zone are bigger (the separation line moves to the plate leading edge) and the critical value of the plate bluntness is smaller than at the cowl absence. Probably, at much bigger value of $X_{0}$ (see Fig. 1a), the global separation can start at some distance from the plate leading edge ("free" separation) even at the presence of cowl. At big height of the inlet $H$, the inlet height can exceed the separation zone height. The described flow has some similarities with the flow ahead a flat obstacle installed on a plate.

Now, an influence of cowl bluntness on the flow will be considered. When the radius of cowl leading edge exceeds a critical value $r_{2}^{*}$, the narrow separation zones formed near the wedges merge into common separation zone 4 (see Fig. $2 b$ ). But there are two differences from the previous case: $(i)$ it happens at some distance from the cowl leading edge where the boundary layer is thick enough; and (ii) the separation flow does not become global because of small thickness of the boundary layer on the cowl.

At much bigger bluntness radius, the bow wave formed ahead the cowl leading edge can reach the plate surface and cause global separation of the plate boundary layer (see Fig. $2 b$ ). This flow is similar to the flow generated by the big plate bluntness. At global separation of the plate boundary layer, the vertical dimension of the flow-capturing area is approximately equal to the inlet height (see Fig. 2b), but the horizontal dimension of the flow-capturing area can be significantly smaller than the inlet width.

\section{INFLUENCE OF COWL PRESENCE ON THE FLOW BETWEEN THE WEDGES}

Figure 3 illustrates flow around the double wedge configuration at two values of plate bluntness $r_{1}$. At $r_{1}=0.75 \mathrm{~mm}$ (Fig. $3 a$ ), the flow between the wedges is regular: no blocking effect can be seen at the absence and at the presence 

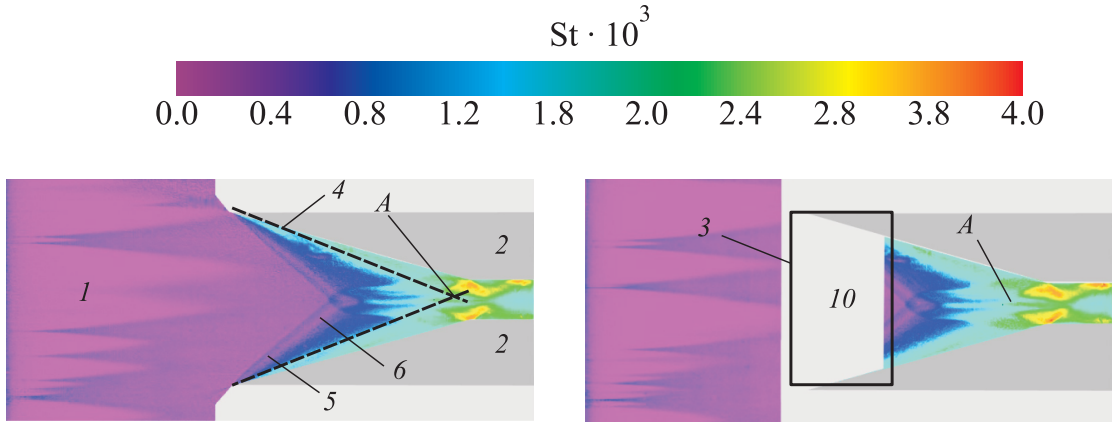

(a)

$\mathrm{St} \cdot 10^{3}$

$\begin{array}{lllllllllll}0 & 2 & 4 & 6 & 8 & 10 & 12 & 14 & 16 & 18 & 20\end{array}$
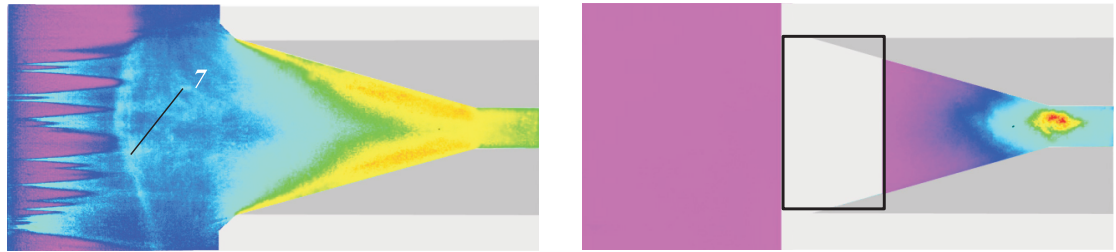

(b)
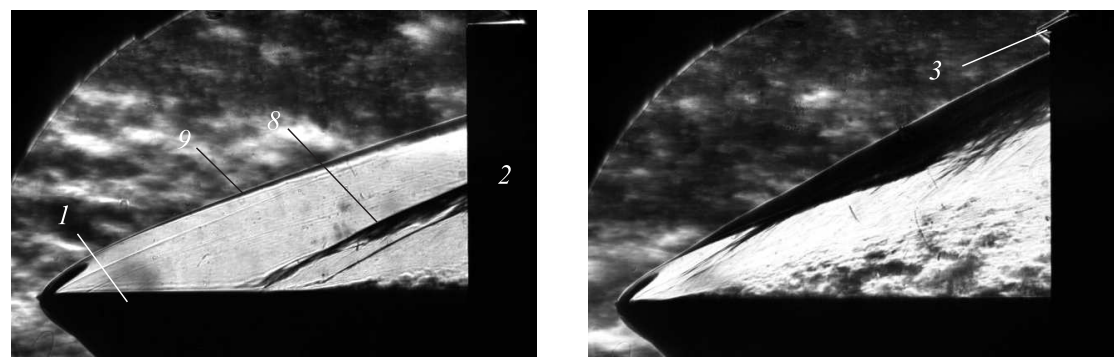

(c)

Figure 3 Stanton number distributions $(a)$ and $(b)$ and schlieren photos $(c)$ at $\mathrm{M}=5$ and $\operatorname{Re}_{\infty L}=23 \cdot 10^{6}$ : left column - at the absence of cowl; right column — at the presence of cowl; $(a)$ plate bluntness $r_{1}=0.75 \mathrm{~mm} ;(b)$ and $(c)-r_{1}=2 \mathrm{~mm} ; 1-$ plate; 2 - wedges; 3 - cowl; 4 - wedge shock; 5 - boundary of shock influence; 6 - line of local separation; 7 - line of global separation; 8 - global separation shock; 9 - bow wave; and 10 - not transparent part of the cowl 
of cowl as well. The Stanton number distributions on the plate at the presence and absence of the cowl are similar. The boundary layer transition ahead the wedges is evident in Fig. $3 a$. The wedge shocks cause significant increase of heat transfer in narrow regions near the wedges. Maximum heat transfer takes place in the rhombus behind the shocks intersection point $A$ (see Fig. 1b).

At the bluntness radius $r_{1}=2 \mathrm{~mm}$ (Figs. $3 b$ and $3 c$ ), the channel formed by the wedges is blocked both at the presence and absence of the cowl. But at the big plate bluntness, the cowl affects significantly on the flow: at the presence of cowl, the separation region is longer than at the absence of cowl. In the second case, the separation line and the separation shock are located between the plate and the wedges leading edges. At the presence of cowl, the flow separates from the plate at its leading edge: Fig. $3 c$ (right column) shows that the separation shock is formed near the plate leading edge and merges with the bow wave. As mentioned above, the separation zone is expanded at the presence of cowl because the cowl prevents the gas outflow from the inlet along the wedges. Obviously, the degree of cowl influence depends on the wedge height.

Stanton number distributions along the plate symmetry line $Z=0$ at the presence and absence of sharp cowl are compared in Fig. 4. Two close bluntness radii are selected for comparison: $r_{1}=0.75$ and $1 \mathrm{~mm}$ (at the presence of cowl, no data are obtained under the nontransparent part of the cowl). The point $O$ corresponds to the wedges leading edges, the point $A$ corresponds to the shocks intersection, and the point $B$ corresponds to the intersection of rarefaction waves emanating from the wedges corner points (see Fig. 1b).

Regular flow takes place in the inlet at smaller bluntness radius $r_{1}=0.75 \mathrm{~mm}$. Stanton number increases slightly at the beginning of the interference region

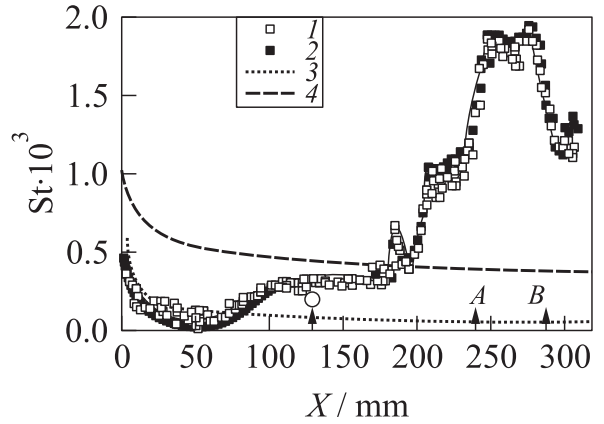

(a)

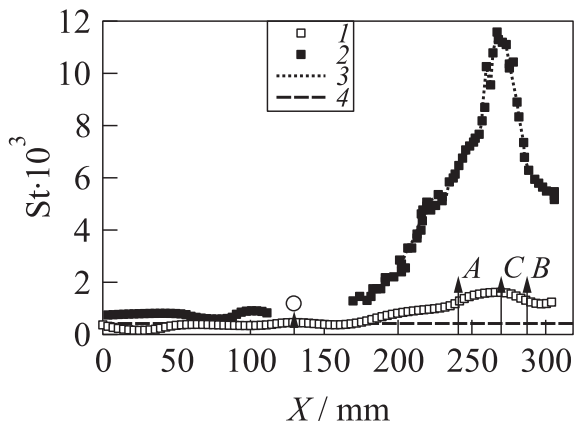

(b)

Figure 4 Stanton number distribution along the symmetry line $Z=0$ at $\mathrm{M}_{\infty}=5$ and $\operatorname{Re}_{\infty L}=23 \cdot 10^{6}$ at $r_{1}=0.75(a)$ and $1 \mathrm{~mm}(b): 1$ - without cowl; 2 - with cowl $\left(r_{2}=0\right) ; 3$ - laminar boundary layer; and 4 - turbulent boundary layer. Signs refer to experiments and curves refer to calculations 
$(X=182 \mathrm{~mm})$, then sharply increases behind intersection of separation shocks $(X \approx 200 \mathrm{~mm})$, and reaches maximal value behind the intersection of wedge shocks (point $A$ ). At $r_{1}=0.75 \mathrm{~mm}$, the Stanton number distributions in the presence and absence of the cowl coincide practically (see Fig. 4a). Thus, at the chosen inlet height $\left(H / W_{0}=0.8\right)$, the flow depends weakly on the presence of cowl. It means also that the flow depends weakly on the inlet height, at least when $H / W_{0}>0.8$. In addition, Fig. 4 shows that heat flux measurements through the transparent wall practically coincide with the results of direct measurements (at the absence of cowl).

At the bigger bluntness radius $r_{1}=1 \mathrm{~mm}$, the channel is blocked both at the absence and at the presence of the cowl. In this case, the global separation zone is formed in front of inlet. According to Stanton number distribution, the boundary layer separates from the plate surface at the point $X=82 \mathrm{~mm}(Z=0)$ in the absence of cowl and at the plate leading edge in the presence of the cowl.

In the case of global separation, the cowl presence has a great effect on heat transfer in the inlet, especially in the throat neighborhood (see Fig. $4 b$ ). In the absence of cowl, the channel blocking does not affect significantly on heat transfer: the maximum value of Stanton number is approximately $1.8 \cdot 10^{-3}$ at the blocking and without it as well. On the contrary, at the presence of cowl, the channel blocking leads to the increase of maximum Stanton number value approximately 6 times from $1.8 \cdot 10^{-3}$ to $11.3 \cdot 10^{-3}$.

\section{INFLUENCE OF PLATE BLUNTNESS ON HEAT TRANSFER AND CHANNEL BLOCKING}

Influence of the plate bluntness radius $r_{1}$ on the flow structure and heat transfer is studied at the presence of sharp cowl (at $\left.r_{2}=0\right)$. Stanton number distributions on the plate and cowl along the symmetry line $Z=0$ are shown in Fig. 5 as an example for two plate bluntness radii: $r_{1}=0$ and $1 \mathrm{~mm}$. The numerical simulation results are shown also in $[35,36]$. Comparison of experimental and calculation results at $r_{1}=r_{2}=0$ (see Fig. $5 a$ ) shows that on the sharp plate, the laminar-turbulent transition finishes in front of the inlet. On the sharp cowl, the laminar-turbulent transition occurs within the inlet in the region of interference between the boundary layer and wedge shocks. The Stanton number in the interference region on the cowl is significantly lower than that on the plate up to the point $A$ of shocks intersection (see Fig. 1b). This is caused by the fact that on the cowl, the shocks interact with the laminar boundary layer and on the plate with the turbulent boundary layer. But behind the shocks intersection point, the data for the plate and cowl coincide practically. It means that behind the point $A$, the laminar-turbulent transition occurs on the cowl too. Additionally, it should be noted that coincidence of predicted and experimental results for the sharp 


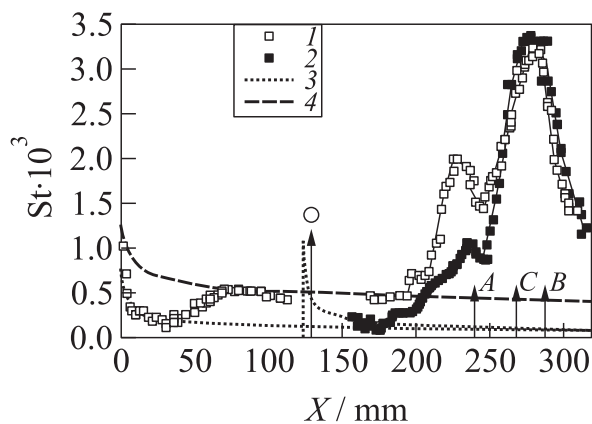

(a)

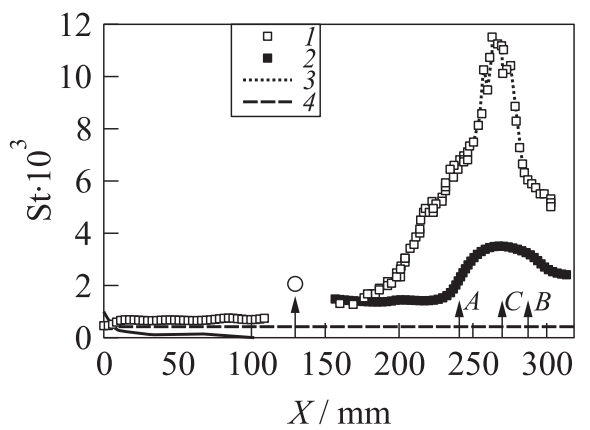

(b)

Figure 5 Heat exchange on the plate (1) and cowl (2) at $\mathrm{M}=5$ and $\operatorname{Re}_{\infty L}$ $=23 \cdot 10^{6}$ : Stanton number distribution along the symmetry line $Z=0$ at $r_{1}$ $=r_{2}=0(a)$ and at $r_{1}=1 \mathrm{~mm}$ and $r_{2}=0(b): 3$ - laminar boundary layer and $4-$ turbulent boundary layer. Signs refer to experiments and curves refer to calculations

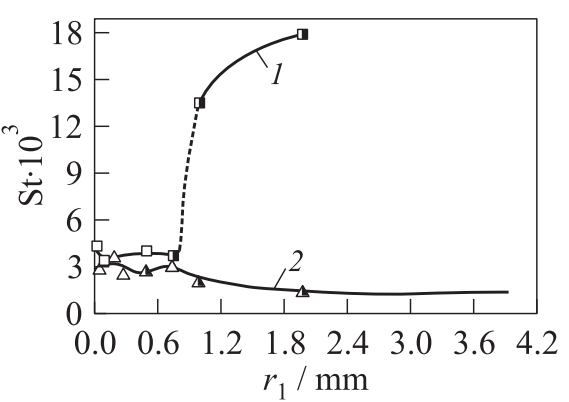

Figure 6 Heat exchange on the plate (1) and cowl (2) at $\mathrm{M}=5$ and $\operatorname{Re}_{\infty L}=23$ $\times 10^{6}$ : Stanton number distribution along the symmetry line $Z=0$ in the cross section 2 vs. the plate bluntness radius $r_{1}$

cowl ahead the transition point indicates the satisfactory accuracy of heat flux measurements on the plexiglass which was used to make the cowl.

Figure $5 b$ presents the Stanton number distributions on the plate and cowl at the plate bluntness radius $r_{1}=1 \mathrm{~mm}$ when the inlet channel is blocked. Comparison with Fig. $5 a$ shows that maximal Stanton number on the plate is increased about 4 times due to the channel blocking while on the cowl, it is increased only slightly. There are several reasons for that: (i) the boundary layer ahead the interference region is turbulent on the plate but laminar on the cowl; (ii) ahead the interference region, the boundary layer on the plate is thicker than on the cowl; and (iii) at $r_{1}=1 \mathrm{~mm}$ and even at $r_{1}=2 \mathrm{~mm}$, the shock generated by the plate separation zone does not reach the front part of the cowl.

Figure 6 presents Stanton number values on the symmetry line $Z=0$ in the section $I I$ situated in the channel throat vs. the plate bluntness radius $r_{1}$. Sharp increase of Stanton number on the plate indicates the blocking of the inlet channel. At $\mathrm{M}=5, \operatorname{Re}_{\infty L}=23 \cdot 10^{6}$, and area contraction of the channel $\eta=W_{0} / W_{t}=4$, it occurs when $r_{1} \approx 0.8 \mathrm{~mm}$ and $r_{1} / W_{t} \approx 0.032$. 


\section{INFLUENCE OF COWL BLUNTNESS ON HEAT TRANSFER AND CHANNEL BLOCKING}

Figures 7 and 8 present an influence of cowl bluntness on flow structure and heat exchange in the inlet with the sharp plate. When the cowl is sharp (see Figs. $7 a$ and $7 c$ ) or blunted slightly, the flow near the cowl surface is regular. It is similar to the flow near the surface of sharp or slightly blunted plate (see Fig. $3 a$ ): oblique shock waves are formed near the wedges; the shocks create two narrow separation zones 5 where Stanton number increases slightly relative to undisturbed region; additional amplification of heat transfer is visible at intersection of two separation zones; significant increase of heat transfer takes place behind the wedge shocks in the reattachment regions 6 and at intersection of these regions (Fig. $7 a$ ).

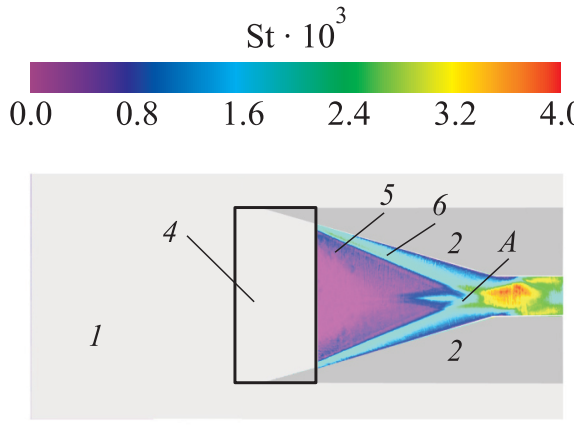

(a)

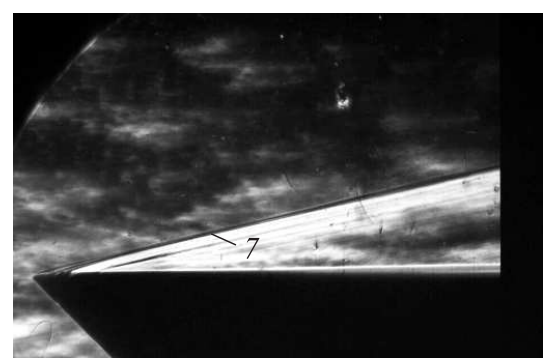

(c)
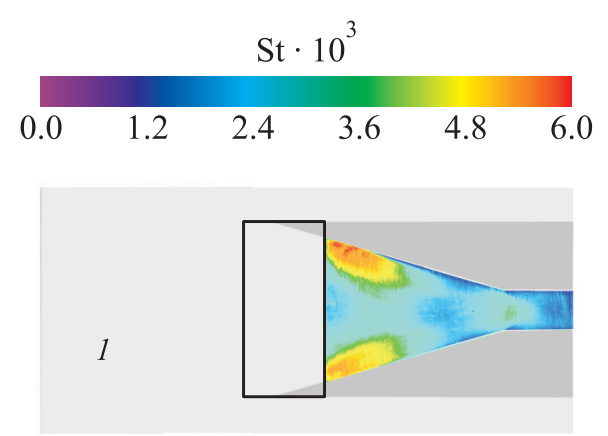

(b)

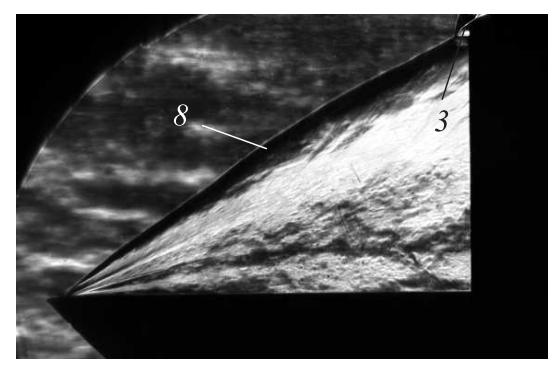

(d)

Figure 7 Stanton number distributions over the cowl surface $(a)$ and $(b)$ and schlieren photos $(c)$ and $(d)$ at $\mathrm{M}=5$ and $\operatorname{Re}_{\infty L}=23 \cdot 10^{6}$ : left column $-r_{1}=r_{2}=0$; right column $-r_{1}=0$ and $r_{2}=2 \mathrm{~mm} ; 1$ - plate; 2 - wedges; 3 - cowl; 4 nontransparent part of the cowl; 5 - separation zone; 6 - reattachment region; 7 weak shock generated by the boundary layer; and 8 - shock generated by the global separation zone 


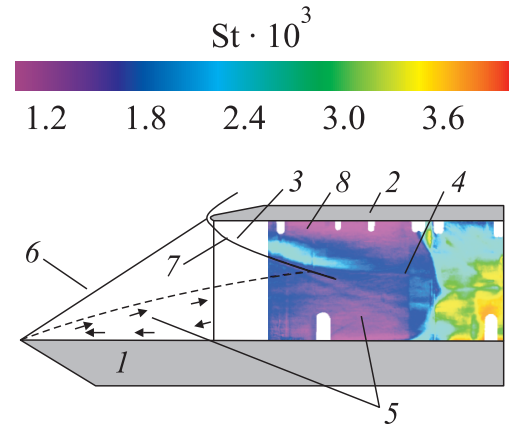

(a)

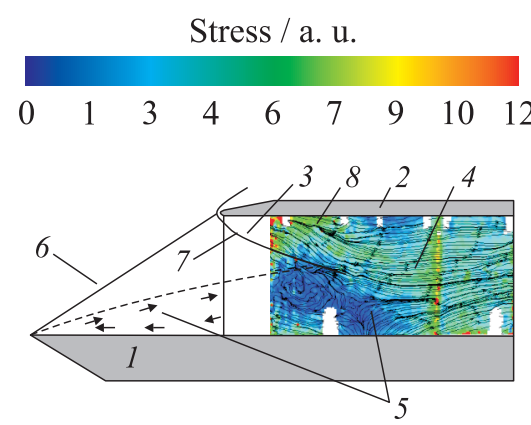

(b)

Figure 8 Flow structure and heat transfer on the wedge in the inlet with sharp plate $\left(r_{1}=0\right)$ and blunted cowl $\left(r_{2}=2 \mathrm{~mm}\right):(a)$ visualization of Stanton number distribution; and $(b)$ visualization of surface limiting streamlines and shear stresses: 1 - plate; 2 - cowl; 3 - wedge; 4 - corner line of the wedge; 5 - separation zone on the plate; 6 - separation shock; 7 - bow wave of the cowl; and 8 - separation zone on the cowl

When the cowl bluntness radius is big enough, the global separation and the blocking of the inlet channel occur similar to the case of big bluntness of the plate. The reasons of this phenomenon are discussed below.

When the cowl bluntness is big and the high-entropy layer is thick, the narrow longitudinal separation zones merge in a common separation zone at some distance from the cowl leading edge. It is indicated by weakening of heat transfer on the cowl surface (see Fig. $7 b$ ), by curving of surface streamlines on the wedge surface in the region 8 (see Fig. $8 b$ ) and by drop of shear stress in this region (decrease of shear stress is reflected qualitatively by the variation of color from red to blue). But it does not lead to the formation of global separation zone and to the blocking of the cowl channel. The reason is small thickness of the boundary layer and correspondingly small dimensions of the separation zone on the cowl surface. But at the chosen height of the inlet, the bow wave generated by the blunted leading edge of the cowl can reach the plate surface (see Fig. 8) and can stimulate separation of the boundary layer on the plate (see Figs. $7 d$ and 8). As a result, the separation zone generates a strong separation shock with big inclination angle (in the example presented in Fig. $7 d$, the inclination angle varies from $36^{\circ}$ near the plate to $28^{\circ}$ near the cowl where the separation shock interacts with the bow wave of the cowl). Thus, the flow formed at big cowl bluntness is similar to the flow at big plate bluntness.

Figures 9 and 10 present an influence of the cowl bluntness on heat transfer on the cowl surface (coordinate system is presented in Fig. 1b). On the sharp cowl, the experimental data ahead the interference region are close to the 


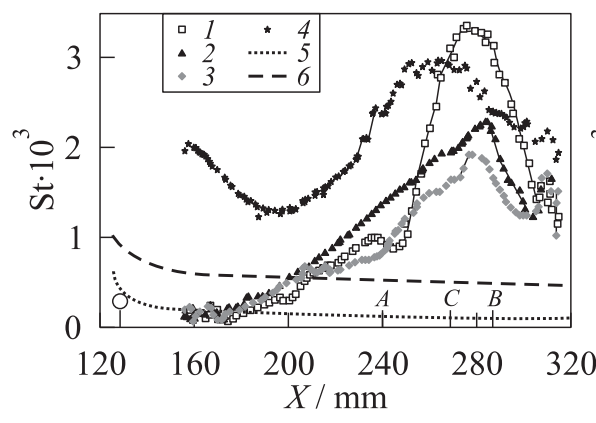

(a)

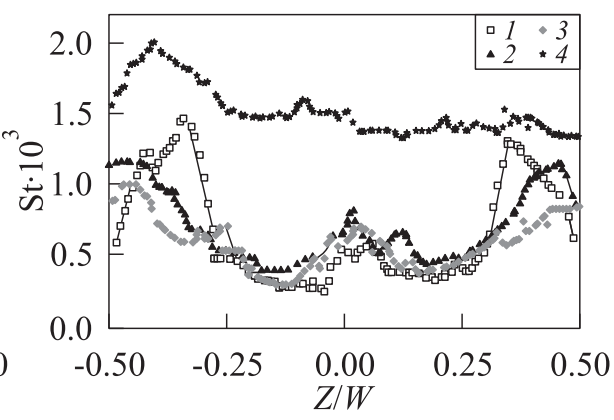

(b)

Figure 9 Heat exchange on the cowl surface at $\mathrm{M}=5, \operatorname{Re}_{\infty L}=24 \cdot 10^{6}$, and $r_{1}=0$ : Stanton number distribution along the symmetry line $Z=0(a)$ and in the cross section $I(b): 1-r_{2}=0 ; 2-0.5 ; 3-1 ; 4-r_{2}=2 \mathrm{~mm} ; 5-$ laminar boundary layer; and 6 - turbulent boundary layer. Signs refer to experiments and curves refer to calculations

St-values calculated for laminar boundary layer (Fig. 9a). On this part of the cowl surface, an increase of cowl bluntness up to $r_{2}=1 \mathrm{~mm}$ has a small effect on heat transfer. First, it is because the boundary layer is kept in laminar state at cowl blunting. On the other hand, relative distance of the observable surface from the cowl leading edge is quite big: even at $r_{2}=1 \mathrm{~mm}$, the ratio $x / r_{2}$ for the observable region is in the range from 30 to 50 . At $r_{2}>1 \mathrm{~mm}$ when the inlet is blocked, the Stanton number on the forward part of the cowl is increased dozen

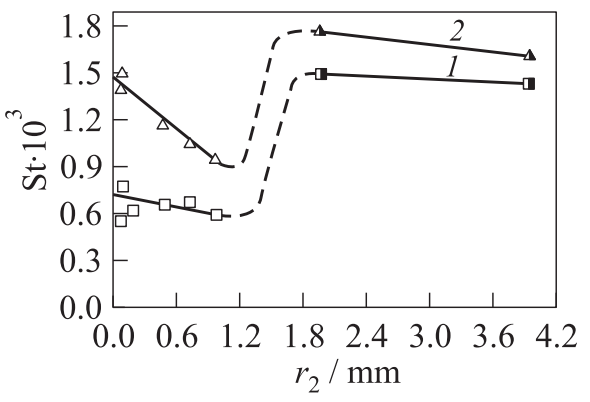

Figure 10 Heat exchange on the cowl surface at $\mathrm{M}=5, \operatorname{Re}_{\infty L}=24 \cdot 10^{6}$, and $r_{1}=0$ : Stanton number in the cross section $I: 1-$ on the symmetry line $Z=0$; and $2-$ maximum value in the cross section $I$ times because of sharp pressure increase behind the bow wave. In the throat neighborhood (behind the point $C$ ), an influence of channel blocking is not so big as in the cowl forward part.

Lateral distributions of St-number on the cowl surface in the cross section $I$ located in front of the throat are shown in Fig. $9 b$ vs. $Z / W$ for different values of bluntness radius $r_{2}$ ( $W$ is the channel width in the cross section $I$ ). At regular flow $\left(r_{2} \leq 1 \mathrm{~mm}\right)$, the heat transfer peaks are clearly visible near the wedges where the separated boundary layer reattaches plate surface. Less significant heat transfer augmentation is visible on the symmetry line $Z=0$. It is caused 
by intersection of separation shocks formed in front of the wedges. At $r_{2}=2 \mathrm{~mm}$ when the inlet is blocked, the distribution of heat transfer coefficient in the cross section is more uniform than at smaller bluntness radii.

Figure 10 presents Stanton number values on the symmetry line and maximum Stanton number value $\left(\mathrm{St}_{m}\right)$ in the cross section $I$. At regular flow, the $\mathrm{St}_{m}$ value drops with an increase of bluntness radius $r_{2}$. As noted in [33], the decrease of heat exchange occurs because of the admixture of high-entropy layer to the mixing layer formed on the external boundary of separation zone that leads to the thickening of the mixing layer and to the decrease of gas density in this layer.

The cowl bluntness causing inlet blocking $\left(r_{2}^{*} \approx 1.5 \mathrm{~mm}\right)$ is significantly bigger than the plate bluntness causing the same phenomena $\left(r_{2}^{*} \approx 0.8 \mathrm{~mm}\right)$. It is caused by different mechanisms of inlet blocking: in the first case, blocking happens due to the influence of cowl bow wave on the plate boundary layer while in the second one, the blocking occurs due to the interference between the wedge shocks and the boundary and high entropy layers of the plate.

\section{REYNOLDS NUMBER INFLUENCE ON THE FLOW IN THE INLET WITH BLUNTED PLATE AND COWL}

The data obtained at $\mathrm{M}_{\infty}=5$ and $\operatorname{Re}_{\infty L} \approx 23 \cdot 10^{6}$ were discussed above. In this chapter, these data are compared with the experimental results obtained at the same Mach number but at smaller Reynolds number $\operatorname{Re}_{\infty L}=13 \cdot 10^{6}$.

Comparison shows (Fig. 11) that decrease of Reynolds number leads to the diminishing of bluntness radius causing inlet blocking: at $\operatorname{Re}_{\infty L} \approx 23 \cdot 10^{6}$, blocking occurs when $r_{1} \approx 0.8 \mathrm{~mm}$ or $r_{2} \approx 1.5 \mathrm{~mm}$ and at $\operatorname{Re}_{\infty L}=13 \cdot 10^{6}$, the same occurs when $r_{1} \approx 0.65 \mathrm{~mm}$ or $r_{2} \approx 0.6 \mathrm{~mm}$. It means that blocking of a channel of high area contraction can be caused by thickening of high-entropy layer as well as of boundary layer in front of the channel throat, as well.

Laminar flow around a ramp with angle more than $180^{\circ}$ at the presence of high-entropy layer is studied in [37]. Sum of high entropy layer thickness and of boundary layer thickness was used as a flow characteristic in this work. Apparently, the ratio of this sum to the throat width $W_{t}$ can be used as a parameter determining the channel blocking.

Some experiments were performed at Mach number $\mathrm{M}=8$ and two Reynolds numbers: $\operatorname{Re}_{\infty L}=6.3 \cdot 10^{6}$ and $3.5 \cdot 10^{6}$. The boundary layer was laminar ahead the channel throat. In both cases, blocking of the channels occurs even at sharp leading edges of the plate and the cowl.

It must be emphasized that all the data presented above are obtained at big area contraction ratio of the channel: $\eta=W_{0} / W_{t}=4$. At smaller contraction ratio $\eta=2$, the cowl blocking did not occur either at $\mathrm{M}_{\infty}=5$ or at $\mathrm{M}_{\infty}=8$. 


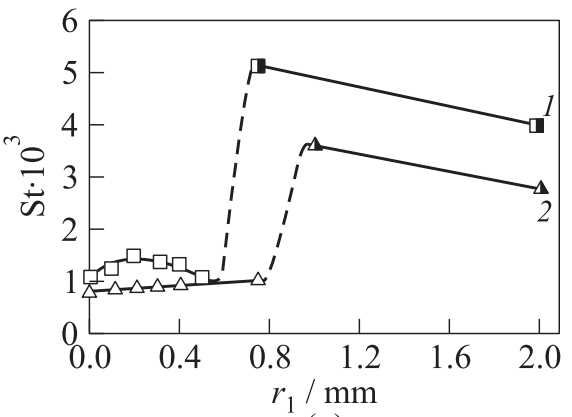

(a)

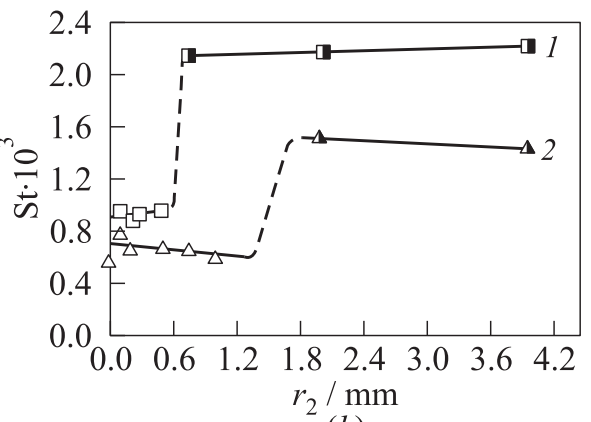

(b)

Figure 11 Reynolds number influence $\left(1-\operatorname{Re}_{\infty L}=13 \cdot 10^{6}\right.$ and $\left.2-\operatorname{Re}_{\infty L} \approx 23 \cdot 10^{6}\right)$ on heat exchange on the plate and cowl surfaces in the cross section $I$ : (a) Stanton number on the plate at $r_{2}=0$; and $(b)$ Stanton number on the cowl at $r_{1}=0$

In addition, it should be noted that the thickness of high-entropy layer depends on pressure ratio $P / P_{\infty}$ where $P$ is the pressure on the plate (or on the cowl) and $P_{\infty}$ is the pressure in front of the model. Increase of $P / P_{\infty}$ (for example, due to the angle of attack) results in decrease of high-entropy-layer thickness at the same bluntness of the leading edge and vice versa.

\section{CONCLUDING REMARKS}

Gas flow and heat transfer in the rectangular inlet installed on the plate at significant distance from the leading edge are studied experimentally at Mach number $\mathrm{M}_{\infty}=5$ and Reynolds numbers $\operatorname{Re}_{\infty L}=23 \cdot 10^{6}$ and $13 \cdot 10^{6}$.

At big area contraction ratio $W_{0} / W_{t}=4$, an increase of plate or cowl bluntness radius up to a critical value leads to a sudden change of the flow structure: a vast separation zone is formed in the inlet. It generates a strong separation shock and leads to significant augmentation of heat exchange inside the inlet.

When the bluntness radii of the leading edges are lower than the critical values, the regular flow is formed in the inlet. In this case, the narrow longitudinal separation zones with separation shocks are created near the wedges. Heat transfer coefficient increases near the reattachment lines and achieves maximum at the intersection of the wedge shocks. At regular flow, increase of leading edges bluntness leads to weakening of heat transfer in the inlet.

The critical values of the plate and cowl bluntness radii are decreased significantly with a decrease of Reynolds number.

At small bluntness radius of the plate corresponding to the regular flow, the presence of the cowl does not affect essentially on Stanton number distribution 
in the inlet. On the contrary, at big plate bluntness corresponding to the inlet blocking, the cowl installation leads to significant intensification of heat transfer in the inlet.

The panoramic optical methods of flow investigation based on the usage of luminescence and intended for short duration wind tunnels were modified. Performed experiments prove the applicability of these methods for studying of external flows as well as of internal flows.

\section{ACKNOWLEDGMENTS}

The research was supported by the Russian Foundation for Basic Research in the frame of Project No. 2011 11-01-00657.

\section{REFERENCES}

1. Kantrowitz, A. 1947. The formation and stability of normal shock waves in channel flows. NACA TN 1225.

2. Vinogradov, V. A., ,V. A. Stepanov, and E. V. Alexandrovich. 1989. Numerical and experimental investigation of an airframe-integrated inlet for high velocities. AIAA Paper No. 89-2679.

3. Marquart, E. J. 1991. Predictions and measurements of internal and external flow field of a generic hypersonic inlet. AIAA Paper No. 91-3320.

4. Kanda, T., T. Komuro, G. Masuya, K. Kudo, A. Murakomi, K. Tani, Y. Wakamatsu, and N. Chinzei. 1991. Mach 4 testing of scramjet inlet models. J. Propul. Power 7(2):275-280.

5. Starukhin, V. G., and A.F. Chevagin. 1994. Influence of front-end edges bluntness on under-wing intake characteristics. Uchenye Zapiski TsAGI XXV(1-2):89-100. [In Russian.]

6. VanWie, D. M., and D. A. Ault. 1996. Internal flowfield characteristics of a scramjet inlet at Mach 10. J. Propul. Power 12(1):158-164.

7. VanWie, D. M. 2000. Scramjet inlets. Scramjet propulsion. Eds. E. T. Curran and S. N.B. Murthy. Progress in aeronautics and astronautics ser. AIAA. Ch. 7. 189:447-511.

8. Goonko, Y.P., A.F. Latypov, I. I. Mazhul, A. M. Kharitonov, M. I. Yaroslavtsev, and P. Rostand. 2003. Structure of flow over a hypersonic inlet with side compression wedges. AIAA J. 41(3):436-447.

9. Falempin, F., M. Goldfeld, R. Nestoulia, and A. Sarov. 2005. Mach 2-Mach 8 experimental evaluation of a simplified variable geometry air inlet. ISABE-20051251. $9 \mathrm{p}$.

10. Lanson, F., and J. L. Stollery. 2006. Some hypersonic intake studies. Aeronaut. J. March:145-156. 
11. Boon, S., and R. Hillier. 2006. Hypersonic inlet flow analysis at Mach 5, 6 and 7. AIAA Paper No. 2006-12.

12. Falempin, F., and F. Wendling. 2006. Experimental investigation of starting process for a variable geometry air inlet operating from Mach 2 to Mach 8. AIAA Paper No. 2006-4513.

13. Neuenhahn, T., and H. Olivier. 2006. Influence of the wall temperature and entropy layer effects on double wedge shock boundary layer interactions. AIAA Paper No. 2006-8136.

14. Häberle, J., and A. Gülhan. 2007. Investigation of the flow field of a 2D scramjet inlet at Mach 7 with optional boundary layer bleed. AIAA Paper No. 2007-5068.

15. Veillard, X., R. Tahir, E. Timofeev, and S. Mölder. 2008. Limiting contractions for starting simple ramp-type scramjet intakes with overboard spillage. J. Propul. Power 24(5):1042-1049.

16. Smart, M. K. 2008. Scramjet inlets. NATO-OTAN, Research and Technology Organization. RTO-EN-AVT-185. 23 p.

17. Wagner, J. L., K. B. Yuceil,. A. Valdivia, N. T. Clemens, and D. S. Dolling. 2009. Experimental investigation of unstart in an inlet/isolator model in Mach 5 flow. AIAA J. 47(6):1528-1542.

18. Krishnan, L., N. D. Sandham, and J. Steelant. 2009. Shock-wave/boundary-layer interactions in a model scramjet intake. AIAA J. 47(7):1680-1691.

19. Mahapatra, D., and G. Jagadeesh. 2009. Studies on unsteady shock interactions near a generic scramjet inlet. AIAA J. 47(9):2223-2231.

20. Throckmorton, R., J. A. Schetz, and L. S. Jacobsen. 2010. Experimental and computational investigation of a dynamic starting method for supersonic/hypersonic inlets. AIAA Paper No. 2010-589. 11 p.

21. Hohn, O., and A. Gölhan. 2010. Experimental investigation on the influence of yaw angle on the inlet performance at Mach 7. AIAA Paper No. 2010-938. 16 p.

22. Hutzel, J. R., D. D. Decker, R. G. Cobb, P. I. King, and M. J. Veth. 2011. Scramjet isolator shock train location techniques. AIAA Paper No. 2011-402.

23. Tan Hui-jun, Li Liu-gang, Wen Yu-fen, and Zhang Qi-fan. 2011. Experimental investigation of the unstart process of a generic hypersonic inlet. AIAA J. 49(2):279.

24. Ogawa, H., and R. Boyce. 2012. Physical insight into scramjet inlet behavior via multi-objective design optimization. AIAA J. 50(8):1773-1783.

25. Borovoy, V. Ya., I. V. Egorov, A. S. Skuratov, and I. V. Struminskaya. 2005. About high entropy layer influence on heat transfer in the region of oblique shock incidence on a truncated plate surface. Dokl. Russ. Akad. Nauk 400(1):1-4. [In Russian.]

26. Borovoy, V. Ya., I. V. Egorov, A. S. Skuratov, and I. V. Struminskaya. 2005. Oblique shock interaction with boundary and high entropy layers of a flat plate. Izv. Russ. Akad. Nauk Mekh. Zhidkosti Gaza 6:89-108. [In Russian.]

27. Borovoy, V. Ya., A. S. Skuratov, and I. V. Struminskaya. 2008. On "threshold" value plate bluntness existence at oblique shock wave interference with boundary and high entropy layers. Izv. Russ. Akad. Nauk Mekh. Zhidkosti Gaza 3:41-52. [In Russian.] 
28. Borovoy, V.Ya., V.E. Mosharov, V.N. Radchenko, and A. Yu. Noev. 2009. Laminar-turbulent flow over wedges mounted on sharp and blunt plates. Fluid Dyn. 44(3):382-396.

29. Borovoy, V. Ya., I. V. Egorov, A.S. Skuratov, I. V. Struminskaya. 2011. Twodimensional interaction of the oblique shock wave with the boundary and highentropy layers of the blunt plate. AIAA Paper No. 2011-731.

30. Borovoy, V. Ya., I. V. Egorov, A. Yu. Noev, A. S. Skuratov, and I. V. Struminskaya. 2011. Two-dimensional interaction between an incident shock and a turbulent boundary layer in the presence of an entropy layer. Fluid Dyn. 46(6):917-934.

31. Borovoy, V. Ya., I. V. Egorov, V.E. Mosharov, A. Yu. Noev, V. N. Radchenko, A.S. Skuratov, and I. V. Struminskaya. 2012. Three-dimensional interaction of oblique shock generated by a wedge with turbulent boundary layer with a presence of an entropy layer. Uchenye Zapisi TsAGI XLIII(6):3-16. [In Russian.]

32. Borovoy, V. Y., I. V. Egorov, A. S. Skuratov, and I. V. Struminskaya. 2013. Twodimensional shock wave/boundary layer interaction in the presence of entropy layer. AIAA J. 51(1):80-93. doi: 10.2514/1.J051496.

33. Borovoy, V. Ya., I. V. Egorov, V.E. Mosharov, V.N. Radchenko, A.S. Skuratov, and I. V. Struminskaya. 2013. Intersecting shock waves interaction with boundary layer on a plate at presence of entropy layer. Izv. Russ. Akad. Nauk Mekh. Zhidkosti Gaza 48(5):79-90. [In Russian.]

34. Mosharov, V.N., and V.N. Radchenko. 2010. New method of flows visualization on an aerodynamic models surface. Sensors Syst. 5:48-53. [In Russian.]

35. Bashkin, V.A. 1964. Drag and heat transfer coefficients calculation of plate, cone, and blunted body at the vicinity of forward stagnation point in laminar boundary layer without dissociation. Proc. TsAGI. 964:12-23. [In Russian.]

36. Avduevsky, V. S., and V.K. Koshkin, eds. 1992. Heat transfer fundamentals in aviation and rocket-space technology. Moscow: Mashinostroyenie. 528 p. [In Russian.]

37. Neyland, V. Ya., and L. A. Sokolov. 1978. Entropy layer influence on boundary layer separation in hypersonic flow. Uchenye Zapiski TsAGI IX(3):36-44. [In Russian.] 